\title{
Os órgãos na ilha Terceira na primeira meta- de do século XIX: elementos introdutórios a uma cartografia organológica
}

\author{
Luís Henriques'
}

\begin{abstract}
Resumo:
Angra foi uma importante cidade do arquipélago dos Açores enquanto centro de passagem das rotas marítimas atlânticas, assento de diocese desde I534 e, na segunda metade do século XVIII, da Capitania-Geral dos Açores. Foram fundadas várias instituições religiosas na cidade desde o século $\mathrm{XVI}$, nomeadamente igrejas paroquiais e conventos, até à sua extinção em 1832 . 0 presente estudo pretende apresentar uma cartografia dos órgãos existentes na ilha Terceira durante esse período, bem como a rede de relações entre instituições e alguns dos indivíduos que estiveram presentes de forma a estabelecer um itinerário virtual de instrumentos, construtores e instrumentistas.
\end{abstract}

\author{
Palavras-chave: \\ Órgão; Música sacra, Paisagem sonora, Ilha \\ Terceira; Século XIX.
}

\begin{abstract}
:
Angra was an important city in the Azores archipelago as passage centre of the Atlantic maritime routes, seat of the diocese since 1534 and, in the second half of the eighteenth century, of the Capitania-Geral dos Açores. Several ecclesiastical institutions were founded in the city since the sixteenth century, notably parochial churches and convents, until their extinction in 1832. The present study aims to present a cartography of the organs in Terceira Island during that period, as well as the network of relations between institutions and some of the individuals that were present in a way to establish a virtual itinerary of instruments, builders and performers.
\end{abstract}

\section{Keywords: \\ Organ; Sacred music; Soundscape; Third Is- land; Nineteenth century.}

A llha Terceira foi nas primeiras décadas do século XIX um dos principais cenários das lutas entre Liberais e Absolutistas, constituindo uma das bases operacionais para as operações de desembarque no continente português. A cidade, elevada a esta categoria em 1535 , foi ao longo do tempo um dos principais centros no trânsito atlântico, constituindo um local ideal para o estabelecimento do novo governo liberal chefiado pelo futuro D. Pedro IV. Em Ponta Delgada (ilha de São Miguel), foi promulgado pelo ministro dos negócios eclesiásticos? Mouzinho da Silveira o decreto de 17 de maio de 1832, chamado da reforma eclesiástica, que reduziu o número de colegiadas e extinguiu as ordens religiosas no arquipélago dos Açores (Costa, 2008: 146). Todavia, as últimas duas décadas do século XVIII e primeiras do XIX corresponderam a um período de grande dinâmica na aquisição de órgãos para as igrejas terceirenses, sobretudo no que

\footnotetext{
I Doutor em Musicologia - Évora - Portugal. Membro do pólo da Universidade de Évora do CESEM e no MPMP (edições mpmp e revista glosas) e consultor do atelier de conservação e restauro Acroarte. Entre 2011 e 2012 realizou o catálogo do fundo musical do Arquivo Capitular da Sé de Angra e, entre 2014 e 20I5, foi bolseiro no projecto “Orfeus”, integrando actualmente o projecto “Música Sacra em Évora no Século XVIII". Em 2012 fundou o Ensemble da Sé de Angra, em 2013 o Ensemble Eborensis com quem gravou um CD. O seu trabalho centra-se na polifonia vocal portuguesa dos séculos XVI e XVII (Sé de Évora) e a música no arquipélago dos Açores desde o povoamento até ao final do século XIX.
} 
Os Órgãos da llha Terceira na I ${ }^{\mathrm{a}}$ metade do século XIX:

elementos introdutórios a uma cartografia organológica

diz respeito às casas monástico-conventuais da cidade de Angra, contrariando o avanço da situação política na ilha. A aquisição destes instrumentos terá constituído um processo de substituição dos mesmos, considerados obsoletos e arcaicos, por novos órgãos mais desenvolvidos em termos sonoros e maiores recursos em termos da registação (Cordeniz, 20 l0: 9-10).

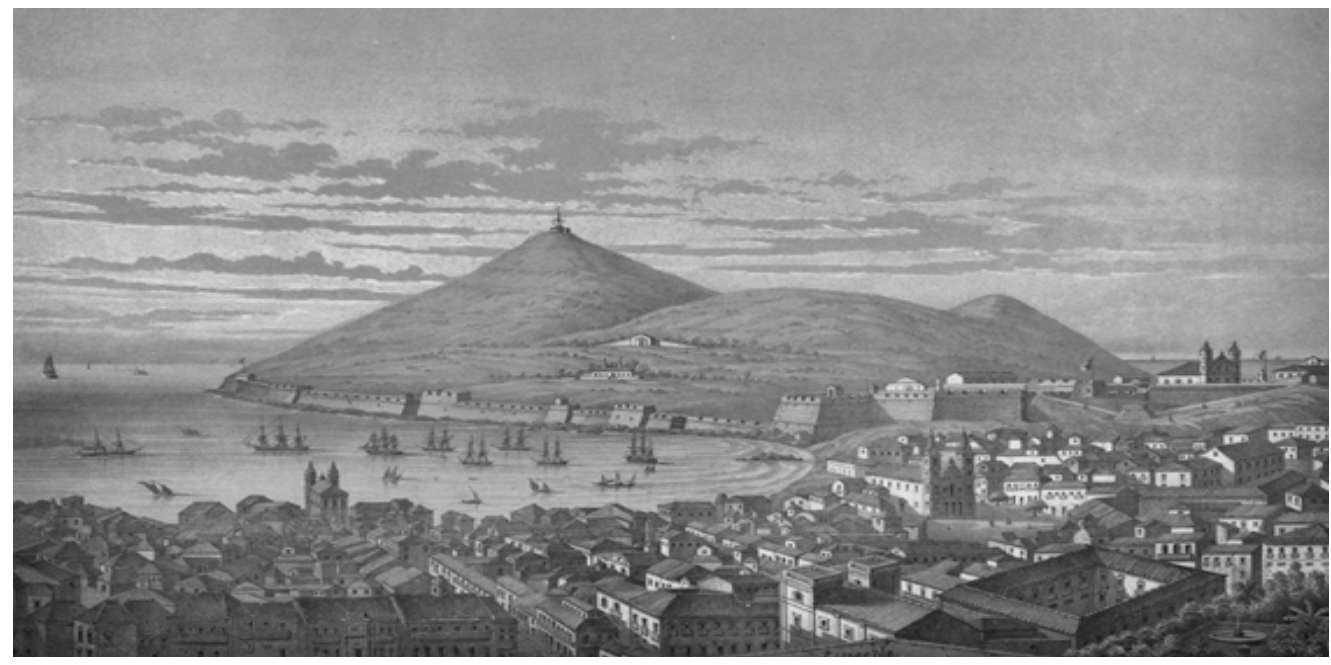

Figura I.Vista de Angra, c.I845 (litografia de Louis Lebreton, http://www.purl. ptl36/8/).

Os órgãos constituem atualmente os últimos testemunhos palpáveis de práticas musicais que outrora integraram a paisagem sonora religiosa da ilha Terceira, assim como dos centros urbanos em geral. Estes instrumentos, frequentemente associados aos respetivos instrumentistas, constituem em muitos casos o elo de ligação mais forte e mais documentado entre as instituições onde estavam localizados e a atividade musical nelas desenvolvida. A presença do órgão na paisagem sonora das instituições religiosas era (e ainda é) de central importância devido à sua centralidade enquanto instrumento ideal para acompanhar o canto, não só pelas suas caraterísticas sonoras, mas também pela associação mística e bíblica no âmbito da Igreja Católica Romana.

A presença dos órgãos em grandes igrejas, como é o caso das Catedrais, igrejas colegiadas e de influentes instituições monástico-conventuais, estabeleceu-se desde a Idade Média e terão certamente estado presentes nas primeiras manifestações litúrgico-musicais das primeiras décadas do povoamento dos Açores, ao longo da segunda metade do século $\mathrm{XV}$. $\mathrm{O}$ organista possuía três ofícios específicos dentro da atividade litúrgico-musical eclesiástica: poderia tocar a solo, tocar em alternância com o cantochão, polifonia ou outros instrumentistas da capela e acompanhar as Missas ou outros momentos do Ofício Divino (Jiménez, 2017: 255). Através do seu ofício dentro da estrutura musical de determinada igreja, conhece-se também a evolução dos instrumentos, assim como o seu estado de conservação. Nos regimentos das catedrais portugueses, no que se refere ao título dedicado ao organista, este tinha como obrigação, para além de tanger o instrumento, também assegurar a sua manutenção bem como o sustento da pessoa encarregada de operar os foles. Para apenas citar dois exemplos, relativamente às catedrais de Elvas e Évora, o organista esta encarregado de tanger durante uma série de ocasiões, nomeadamente na entrada ou saída do Prelado da igreja, Horas Canónicas e missas e sempre que o mestre de capela assim o ordenasse. Não poderia ausentar-se da cidade sem licença do Cabido e, se o fizesse, teria que deixar substituto com capacidade para o de- 
sempenho do respetivo cargo (Alegria, 1985: 104-105). No caso da Catedral de Elvas, o regulamento (que data de 1572) determinava também as ocasiões litúrgicas em que o organista estava obrigado a tocar os órgãos e a sua manutenção, estipulando as penas a aplicar no incumprimento das mesmas funções (Alegria, 1985: 128).

No que diz respeito à ilha Terceira, existe uma concentração de órgãos sobretudo na cidade de Angra do Heroísmo, com cinco exemplares sobreviventes, na cidade da Praia da Vitória, com um exemplar, e na freguesia de Santa Bárbara, também com um único exemplar. Porém, as fontes históricas revelam também a existência de outros instrumentos, entretanto desaparecidos (como é o caso dos órgãos da Catedral), o que enriquece ainda mais o património organístico atual.Angra do Heroísmo é, desde 1983, cidade património mundial da Humanidade, um estatuto atribuído com base no conjunto edificado histórico, mas também num conjunto de instituições que desempenharam um papel determinante ao longo da sua história. Enquanto outras artes, como a arquitetura, pintura ou escultura têm vindo a ter um lugar central ilustrando a riqueza cultural desta cidade ao longo do tempo, outras manifestações artísticas - neste caso particular, a Música - são geralmente remetidas para um plano secundário, talvez como resultado da sua própria essência estética enquanto arte do tempo. A Música esteve omnipresente na paisagem sonora de Angra desde que este nome começou a ser utilizado para designar o aglomerado populacional no local onde hoje está implantada a cidade.

Um dos aspetos mais importantes da prática musical e que englobava grande parte da vivência diária centrava-se no cerimonial litúrgico, designado litúrgico-musical porque, de fato, tratava-se de uma liturgia predominantemente cantada, sobretudo em cantochão. Para além de um grupo de cantores, geralmente clérigos, que estavam encarregados dessas celebrações, um dos ofícios mais importantes e que tinha como função o acompanhamento do canto era o do organista ou tangedor dos órgãos. Como tal, são várias as referências a este ofício na documentação eclesiástica relacionada com Angra, praticamente desde a fundação da Diocese em 1534 até ao final do século XIX.Angra possuía no final do século XVIII três conventos masculinos e três mosteiros femininos localizados por toda a cidade, para além da Catedral e quatro igrejas paroquiais assim como de várias ermidas com variados graus de importância dentro da hierarquia eclesiástica da urbe terceirense. Em termos sonoros seria grande o impacto musical em quem atravessasse a cidade pelas principais ruas desde a atual Rua da Guarita até ao Alto das Covas, descendo a Rua do Galo e subindo a Rua da Sé, onde se localizavam grande parte destas instituições religiosas.

Sobre a experiência sonora sob uma perspetiva histórica veja-se o exemplo do projeto de paisagem sonora histórica aplicado às cidades de SeviIha e Granada, onde uma série de eventos históricos de natureza musical são adicionados regularmente proporcionando uma série de roteiros temáticos em torno das práticas musicais em contexto urbano ${ }^{2}$. Estas incluem a atividade das capelas de música das várias igrejas das cidades, as referências aos sons que se poderiam ouvir nas ruas, assim como a presença de instrumentos e instrumentistas, não só na vida musical secular como também religiosa, tendo os órgãos um papel principal neste último contexto. Os roteiros contemplam a aquisição destes instrumentos para as instituições religiosas, através de contratos, escrituras e outra documentação, como também a presença de organistas nesses

2 Projeto desenvolvido por Juan Ruiz Jiménez, disponível em http://www.historicalsoundscapes.org (consultado junho 20, 20I8). 
Os Órgãos da llha Terceira na I ${ }^{\mathrm{a}}$ metade do século XIX:

elementos introdutórios a uma cartografia organológica

espaços e a sua circulação por outras instituições.

Desta forma, são possíveis vários roteiros em torno da presença dos órgãos na ilha Terceira. Por um lado, primeiramente, o seu próprio itinerário, um percurso pelos seus construtores, nomeadamente António Xavier Machado e Cerveira (o construtor mais representado) e, por último, o contexto musical a que estes instrumentos estavam associados nas instituições musicais representadas (Machado e Doderer, 20I2).A sua importância ilustra, não só o percurso dos instrumentos que se encontram atualmente na ilha, como ainda aqueles cuja existência é referida no início do século XIX, mas que, ou perderam-se, ou foram transferidos para outras localizações. Nestes últimos casos são numerosas as ocorrências, permitindo o itinerário virtual reconstruir não só as várias localizações, como também os vários contextos litúrgico-musicais, em alguns casos, a única opção para se conhecer a existência dos instrumentos. Partindo dos dados documentais disponíveis até ao momento, este não é um itinerário linear, mas sim uma teia de relações musicais que se estende no tempo, com particular incidência nas últimas décadas de setecentos e primeiras de oitocentos. Não constituindo um processo fácil a decifração destas relações, parte-se da história de cada instrumento para a informação contextual, no que se refere à sua aquisição e manutenção, assim como os indivíduos a ele relacionados, como é o caso dos organistas. Os templos que possuem ou possuíram órgãos inserem-se em várias tipologias, desde igrejas seculares (como a Catedral e a Colegiada de Nossa Senhora da Conceição) a igrejas de instituições conventuais masculinas e femininas.

De todas as igrejas da ilha Terceira a Catedral é aquela que domina a hierarquia eclesiástica não só da ilha, mas também de todo o arquipélago, por ser sede da respetiva diocese desde 1534. Esta condição obrigou a que o seu serviço litúrgico-musical estivesse organizado desde pelo menos meados do século XVI. Este era constituído pelo grupo de capelães encarregados de cantar os vários ofícios diários e missas, dirigidos por um mestre de capela, e um tangedor dos órgãos. Este último começou a receber oito mil réis anuais por tanger os órgãos a 18 de outubro de 1540 (Witte, 1972: I55). No seguimento do que atrás foi referido acerca das funções do organista, este estava encarregado de tocar nas várias ocasiões durante a Missa e o Ofício Divino, acompanhando a capela da Catedral sempre que se justificasse. À data do Decreto de 17 de maio de 1832, contava a Catedral de Angra com o respetivo organista, mestre de capela e um grupo de capelães-cantores. Referindo-se aos órgãos, o Padre Jerónimo Emiliano d'Andrade afirmava em I 843 que eram "mui notaveis neste Templo o órgão, um dos maiores e mais excelentes que se encontram em Portugal" (Andrade, I89I: I 10). À época em que escrevia, Andrade estaria a identificar o órgão instalado na década de 1780 e o órgão anterior ao de Joaquim Silvestre Serrão. Por essa época, sabe-se terem exercido o cargo de organista na Catedral no final do século XVIII e primeiras décadas de oitocentos o Padre José Benedito, sucedendo-lhe o seu discípulo nesse ofício o Padre Manuel Caetano (Mota, 2007: 36-37).

No final do século XVIII surgiu a possibilidade de adquirir um novo órgão para a Catedral. A documentação é praticamente inexistente no que diz respeito ao processo da sua vinda para a Catedral, porém, o relato que circulou ao longo dos séculos XIX e XX parece, por si só, suficientemente interessante como informação contextual a adicionar ao instrumento, embora ressalvando as lacunas documentais. $O$ Padre Manuel Azevedo da Cunha refere que o "grande orgam d'aquela catedral, que se destinava a Macau, tendo vindo da Alemanha 
para a Terceira em navio que não poude seguir viagem. Este grande orgam ficou em Angra, oferecido á Sé por D. Maria I. a, e custou 3 contos (Cunha, 1924: 293-294). O mesmo foi repetido por vários autores que mencionaram o instrumento (Costa, 1867: 94; Sampaio, 1904: 224; Gablenz, 1959-60; Mota, 1986: 8). Gerou-se aceso debate nas décadas de 1970 e 1980 sobre a origem deste órgão, dividindo-se os autores entre a origem alemã (Mota, 1986: 8-9), e ainda os construtores, atribuindo-se a António Xavier Machado e Cerveira a sua construção (Gablenz, 1959-60) e Joaquim António Peres Fontanes (Pereira, 1986; Machado e Doderer, 2012). Gablenz transcreveu uma suposta etiqueta que existia por cima do teclado com a inscrição "ANTONIO XAVIER MACHADO E CERVEIRA 1793, No 10 | Acabado a 2 de Setembro" (Gablenz, 1959-60: 50I). Todavia, a data de construção do instrumento não corresponde ao período indicado no relato da sua chegada a Angra. Um outro pormenor cronológico refere-se à presença de D. João Marcelino dos Santos Homem Aparício em Angra como Bispo da respetiva diocese de 15 de agosto de 1775, data da sua chegada a essa cidade, até à data da sua morte a 21 de maio de 1782. Desta forma o órgão teria sido pedido à Rainha D. Maria I entre 1775 e I782³. No estudo realizado sobre os órgãos de Machado e Cerveira conhecidos em Portugal, embora o número I0 não apareça na lista, as datas de I785, que corresponde ao número 3 e I787, que corresponde ao número seguinte conhecido (o número 16 ), inviabilizam a data apontada por Gablenz (Cordeniz, 20 I0: 77).

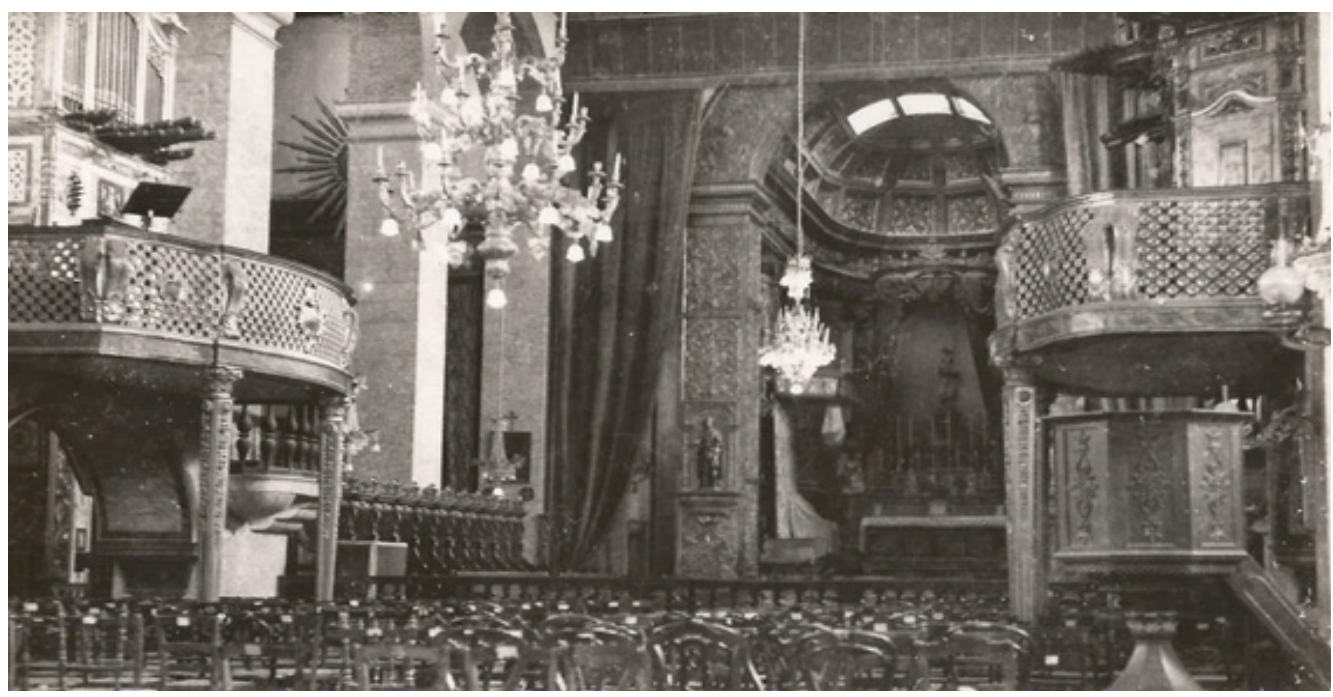

Figura 2.A Catedral de Angra no início do século XX. Postal (Loja do Buraco, Angra).

Este órgão, denominado popularmente como “órgão grande” ou “órgão de D. Maria", estava localizado na nave central, do lado da Epístola em coreto próprio debaixo de um arco, fronteiro a outro coreto que também sustentava um órgão (Figura 2). Era um instrumento com muitos recursos como se poderá depreender do esquema da registação e outros recursos técnicos publicado por Gablenz (1959-60: 495-499).

3 A autoria do instrumento é atribuída a Joaquim António Peres Fontanes de forma veemente por Machado e Doderer (2012: 9I) sem, porém, ser apresentada qualquer referência documental que a sustente: "O órgão grande foi cedido pela rainha D. Maria II à Sé de Angra do Heroísmo [...]. Após vários anos depositado em terra firme, sempre com as indicações do seu construtor, Joaquim António Peres Fontanes, o Bispo de então, solicitou à Rainha o instrumento". 
Os Órgãos da llha Terceira na I ${ }^{\mathrm{a}}$ metade do século XIX:

elementos introdutórios a uma cartografia organológica

Já um pouco desfasado em termos das balizas temporais delineadas para o presente estudo é o órgão construído em 1854 por João Nicolau Ferreira sob direção do Padre Joaquim Silvestre Serrão, importante compositor e mestre de capela ativo na cidade de Ponta Delgada em meados do século XIX, e instalado em coreto próprio do lado do Evangelho (Figura 2). Porém, a inclusão deste instrumento nesta cartografia organológica reveste-se de alguma importância por ter sido identificado o "novo" órgão de meados do século XIX ter sido incorporado num instrumento já existente e que, certamente seria do período aqui tratado ou anterior. $O$ órgão foi utilizado pela primeira vez a 16 de setembro de I854, dia do aniversário de D. Pedro V, certamente no ofício de Te Deum que era usual cantar-se na Catedral pelos aniversários reais (Andrade, I891: II0).

Em artigo publicado em 1986 o organeiro Luís Esteves Pereira, que havia estado na Catedral a trabalhar nos dois órgãos, referindo-se ao órgão de Serrão, afirma que a sua caixa seria provavelmente de meados do século XVIII. Os painéis e puxadores dos registos haviam sido aplicados sobre uma caixa anterior repintada. Reparou ainda que vários tubos tinham sido assentes em orifícios anteriores (Pereira, 1986:8). Fazendo fé na descrição de Pereira, poderá colocar-se a hipótese de se tratar de um instrumento antigo, posteriormente "modernizado" ou cujos materiais foram reaproveitados por Ferreira e Serrão de forma a corresponder a um instrumento à altura do local a que se destinava. O órgão de menores dimensões que existia na Catedral foi vendido para a igreja paroquial de São Pedro (Figura 3) por cem mil réis em data incerta, após a instalação do órgão de Serrão em 1854 (Andrade, I89I: I37). No início do século $X X$ o instrumento surge identificado no coro-alto da igreja (Sampaio, 1904: 236). Porém, no início da década de 1980 servia já como armário para paramentos, localizado na sacristia da igreja. De destacar a decoração da caixa de carvalho, com elementos de chinoiserie datados do século XVII (Martins, 198I: 147). A comprovar-se a datação da caixa, trata-se dos restos de um dos instrumentos musicais mais antigos existentes no arquipélago e, certamente, o órgão mais antigo. Terá sido este órgão aquele que esteve em serviço na Catedral ao longo de todo o século XVIII que, pela estrutura "de armário", teria sido usado em vários pontos deste templo. Comparando as dimensões com aquelas do órgão de Joaquim Silvestre Serrão percebe-se que este último estaria certamente numa localização fixa, sendo o outro um caráter mais portativo. Estas caraterísticas foram testemunhadas pelo Padre Manuel Azevedo da Cunha que refere tratar-se de "um organete amovível, que em 1874, data de nossa entrada no seminário, existia na egreja de S. Pedro d'aquela cidade (Cunha, 1924: 294).

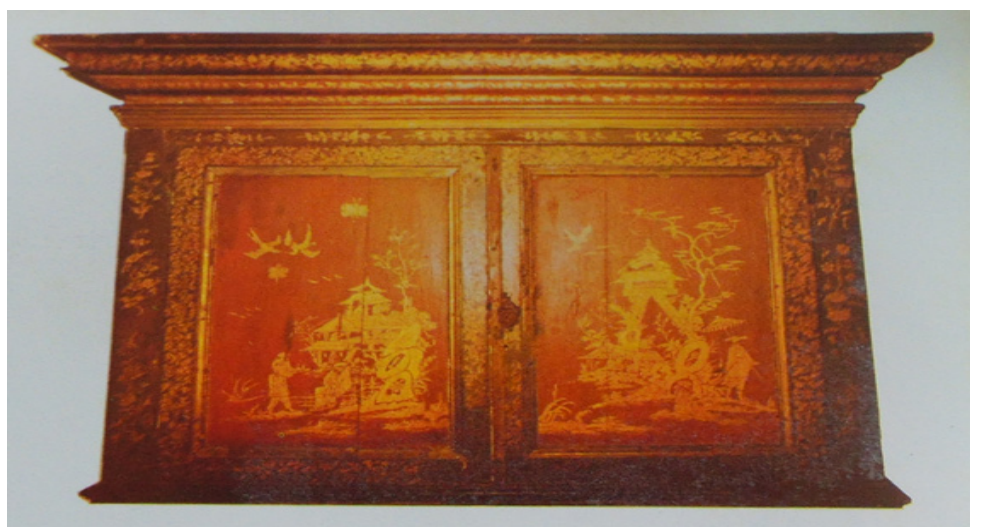

Figura 3. Parte da caixa do órgão da igreja de São Pedro, c. século XVII (atualmente armário de paramentos) (Martins I98I, I47). 
Na Igreja de São Pedro existia previamente um órgão. Foi o mesmo vendido para a Igreja de São Bartolomeu aquando da aquisição órgão da Catedral por oitenta mil réis (Andrade, I89I: I37).

A I de Janeiro de 1980 ocorreu na ilha Terceira um violento terremoto que destruiu grande parte da cidade e arruinou profundamente a Catedral, fazendo ruir parte da parede da capela-mor e as capelas laterais de Santo Estêvão e São Pedro. A 5 de julho de 1983, já com as obras de recuperação em andamento, ruiu uma das torres e grande parte do frontispício. A 25 de setembro do mesmo ano deflagrou um incêndio que consumiu todo o interior do templo. Este, para além de toda a talha, também destruiu a caixa do órgão grande consumindo totalmente o órgão construído por Joaquim Silvestre Serrão (Mota, 2007: 185-186).A máquina do órgão grande, que havia sido desmontada em I98I para posterior intervenção de restauro, sobreviveu ao incêndio sendo mais tarde incorporada no órgão que o mestre organeiro Dinarte Machado construiu para a Catedral (Pereira, 1986: 8).

A segunda igreja em termos de importância na esfera eclesiástica de Angra era a colegiada de Nossa Senhora da Conceição ereta em paróquia por volta de meados do século XVI. Era uma das poucas igrejas paroquiais de Angra que desde cedo teve posto de organista. O Decreto de 17 de maio de 1832 reduziu esta colegiada a vigário, dois curas e tesoureiro, extinguindo-se o posto de organista que, tal como os beneficiados, foi incorporado na Catedral (Drumond, 1990: 217). O órgão que atualmente pode ser encontrado no coro-alto da igreja foi inicialmente instalado em coreto próprio junto ao transepto, tal como os da Catedral. $O$ instrumento foi concedido à colegiada da Conceição por portaria do Ministério do Reino de 20 de dezembro de 1832 e entregue quatro anos depois. Este é um exemplo de um instrumento que pertencia a uma comunidade religiosa regular (neste caso feminina), o convento de clarissas de Nossa Senhora da Luz da vila da Praia, e que após a extinção das ordens foi vendido ou cedido a igrejas seculares (Costa, 1867: 106). No início do século XX encontrava-se já instalado no local atual (Sampaio, 1904: 233). Trata-se de um órgão construído por António Xavier Machado e Cerveira no ano de 1815, com o número $8 \mathrm{I}$, ao qual foi retirado o resplendor de forma a poder ser incorporado no coro-alto da igreja. Em termos das suas caraterísticas técnicas, trata-se de um instrumento semelhante ao número 78 construído por este organeiro e que se encontra atualmente na Igreja Matriz de São Salvador na cidade da Horta (ilha do Faial) (Cordeniz, 20I0: 42). Estas semelhanças contextuais sugerem a possibilidade de também o órgão do Faial ter também pertencido a alguma casa monástico-conventual, nomeadamente franciscana, apesar de esta não estar ainda sustentada com documentação coeva.

A outra igreja secular onde existe um órgão construído no período estudado é a Igreja Matriz de Santa Cruz, na cidade da Praia da Vitória, uma igreja colegiada em que se conhece existir já em I549 o cargo de tangedor dos órgãos, pago pela Câmara (Drumond, 1990: 258). Desconhece-se se o posto de organista existiria ainda em I832, mas, tal como ocorreu na Igreja da Conceição de Angra, também o Decreto da reforma eclesiástica reduziu os cargos da Igreja de Santa Cruz ao mínimo. Existe atualmente nesta igreja um órgão construído por António Xavier Machado e Cerveira no ano de I793, com o número 40. Trata-se de um dos maiores instrumentos inseridos numa estrutura de armário construídos por esse organeiro e, do ponto de vista organológico, um importante exemplo para o estudo dos processos construtivos da sua oficina de organaria (Cordeniz, 20 I0: 34-35). O instrumento encontra-se localizado ao nível 
Os Órgãos da llha Terceira na I ${ }^{\mathrm{a}}$ metade do século XIX:

elementos introdutórios a uma cartografia organológica

do chão da igreja debaixo de um dos arcos da nave central do lado da Epístola. Este templo sofreu danos profundos com os vários terremotos que abalaram a Praia da Vitória ao longo dos séculos. Desta forma, não é possível perceber se o instrumento esteve sempre na localização atual ou se foi transferido de um local anterior.A forma como está colocado é um pouco atípica relativamente às igrejas de Angra, onde era frequente a construção de coretos próprios, podendo ter sido este o caso da Matriz de Santa Cruz uma vez que este templo não possui coro-alto.

A 21 de outubro de 1728 foi lançada a primeira pedra para a construção da nova igreja da Santa Casa da Misericórdia de Angra, que terá custado 350 mil cruzados. A bênção do templo ocorreu a 4 de junho de 1746 pelo vigário-geral da diocese Manuel dos Santos Rolim, mestre-escola da Catedral (Andrade, 189I: I24-125). Tratou-se de uma empresa de considerável dimensão a construção de um edifício que ainda hoje possui um porte imponente junto ao Pátio da Alfândega, nas antigas portas da cidade. Porém, ainda não estaria concluída a igreja na sua totalidade na década de 1840, uma vez que as janelas das galerias laterais "tapadas com portas de madeira tornam a egreja um pouco escura, e menos agradavel" (Andrade, I89I: 124). No pequeno coro-alto, por cima da entrada principal, foi instalado um órgão construído por António Xavier Machado e Cerveira no ano de 1829, com o número 104. Este é um instrumento gémeo de outro (com o mesmo número) construído por Machado e Cerveira em I 828 para o convento de Santo André de Ponta Delgada. Trata-se de um instrumento de construção já tardia, com o abandono de algum tipo de registos, nomeadamente alguns flautados e Voz Humana, tornando o instrumento algo desequilibrado em termos sonoros (Cordeniz, 2010: 55-56).

Em meados do século XVIII foram expulsos do arquipélago dos Açores os religiosos da Companhia de Jesus ficando assim os três colégios que possuíam em Ponta Delgada, Horta e Angra. No caso da Igreja de Santo Inácio de Loiola, anexa ao Colégio de Angra, ficou a mesma reduzida a capela do Palácio dos Capitães-Generais até ao início do século XIX (Costa, 1867: 104). Por volta do ano de 1787 foi decidido instalar-se um Seminário diocesano no edifício do Colégio, para o qual se tomaram várias diligências entre o Bispo e o então capitão-general Dinis Gregório de Melo, porém, sem sucesso (Drumond, I859: 62-63). A igreja passou a capela do Palácio dos Capitães-Generais e em 1804 mudou-se para aí a Ordem Terceira de Nossa Senhora do Carmo, estabelecida desde 1766 na Igreja da Misericórdia. Desentendimentos com a mesa da Misericórdia levaram a que se trasladasse a imagem de Nossa Senhora do Carmo para a igreja do Colégio a 17 de março de 1804, passando esta a denominar-se de Nossa Senhora do Carmo a partir dessa data (Andrade, I89 I: |3 I-I32). O órgão que existe atualmente no coro-alto da igreja foi construído por António Xavier Machado e Cerveira no ano de 1798, com o número 56. Os elementos decorativos deste instrumento afastam-se de uma estética barroca, aproximando-se de um neo-classicismo através da aplicação de linhas direitas. Trata-se de um instrumento inovador, não só em termos da decoração, como através da introdução de novos pormenores técnicos e sonoros, nomeadamente nos anuladores de palhetas, teclado com uma maior extensão entre outros (Cordeniz, 2010: 37-38).

Tanto o órgão da Igreja do Colégio como o da Misericórdia, e ainda juntando o da Matriz de Santa Cruz da Praia da Vitória, levantam algumas dúvidas quanto à sua colocação nesses templos, assim como a sua proveniência. No caso do instrumento da Igreja do Colégio, a sua data de construção afasta-o comple- 
tamente de um contexto jesuítico. Como se sabe a própria Companhia de Jesus estava mais vocacionada para a pregação e evangelização, não constituindo a celebração dos ofícios litúrgico-musicais uma função central na sua ação religiosa. Como tal, a aquisição do órgão construído em I 798 foi feita já noutro contexto, talvez bastante mais tardio até, muito possivelmente dentro das atividades da Ordem Terceira de Nossa Senhora do Carmo.

Embora a Misericórdia tivesse organista próprio, a construção do novo templo setecentista terá implicado também uma série de inovações, embora o mesmo ainda não estivesse concluído no início do século XIX. Francisco Ferreira Drumond, ao referir-se a esta igreja em meados do século XIX, classifica o órgão aí existente como medíocre (Drumond, 1990: 216). Desconhece-se se o autor referia-se ao órgão de Machado e Cerveira ou a outro instrumento de inferior qualidade. Todavia, uma vez que Drumond era organista e profundo conhecedor deste tipo de instrumentos, existe uma forte probabilidade de se estar a referir a outro instrumento. Este comentário não faria sentido com o conhecimento que certamente teria dos outros instrumentos existentes na ilha que à época partilhavam as mesmas caraterísticas com o instrumento da Misericórdia. $O$ comentário de Drumond sugere ainda que o instrumento que hoje se encontra na Igreja da Misericórdia terá sido aí instalado muito após a data de construção nele existente. Uma vez mais, não será de excluir que o órgão tivesse proveniência em alguma das instituições monástico-conventuais extintas. Esta probabilidade acentua-se ao olhar-se para o contexto do instrumento-gémeo, construído no ano anterior para o convento de clarissas de Santo André de Ponta Delgada. Embora não se tenham encontrado ainda quaisquer referências documentais poderá, contudo, colocar-se a hipótese deste instrumento da Misericórdia ter pertencido a algum convento de clarissas terceirense que, excluídos os que se conhecem terem possuído órgãos, remete para o convento de Jesus da Praia ou o de Nossa Senhora da Esperança de Angra, esta última uma casa de grande atividade litúrgico-musical, com uma comunidade igual ou superior a sessenta religiosas. $O$ mesmo ocorre com o órgão da Matriz da Praia, cuja proveniência se desconhece, mas que também poderia ter vindo de algum dos conventos acima mencionados ou do convento de religiosos franciscanos que aí existiu.

Uma percentagem considerável dos órgãos existentes na ilha Terceira encontrava-se direta ou indiretamente relacionada com Ordem Franciscana, que se estabeleceu no arquipélago dos Açores praticamente desde que chegaram às ilhas os primeiros povoadores no século XV. Estes religiosos foram-se expandindo por oito das nove ilhas, adquirindo uma profunda influência na religiosidade no arquipélago através de demonstrações e participação nos cerimoniais litúrgicos (nomeadamente nas procissões) criando grande impacto nas sociedades locais. Angra estabeleceu-se como sede da recém-criada Província de São João Evangelista em 1640 em resultado da eleva da custódia açoriana (Costa, 2008: 138). Posteriormente, esta província foi desmembrada em duas custódias, surgindo a segunda em $1717 \mathrm{com}$ sede em Ponta Delgada englobando as ilhas de São Miguel e Santa Maria (Costa, 2008: I38- I39). As casas franciscanas, tanto do ramo masculino como do feminino, tiveram uma importância determinante na aquisição de órgãos nas últimas décadas do século XVIII e primeiras do XIX (Machado e Doderer, 20I2: 9-10).Após a extinção destas instituições os instrumentos foram vendidos pela Fazenda Nacional sendo muitos deles adquiridos pelas Juntas de Paróquia para as respetivas igrejas onde de se encontram atualmente, como foi o caso da Igreja de Nossa Senhora da Conceição e de Santa 
Os Órgãos da llha Terceira na I ${ }^{\mathrm{a}}$ metade do século XIX:

elementos introdutórios a uma cartografia organológica

Bárbara, os dois casos conhecidos e documentados na ilha Terceira.

O primeiro destes casos refere-se ao convento de São Francisco de Angra, onde se encontra atualmente o primeiro órgão construído por António Xavier Machado e Cerveira para o arquipélago dos Açores com o número 22, datado de 1788 (Cordeniz, 20 I0: 26), mantendo-se no local original onde foi instalado em coreto próprio do lado do Evangelho junto ao coro-alto (Andrade, I89 I: II9). Este foi talvez o mais importante convento franciscano do arquipélago, sede da Província de São João Evangelista. No que diz respeito à atividade organística nesta instituição, na última década do século XVIII e primeiras do XIX está identificado como organista Fr. António de Pádua, que ocupou também o cargo de vigário do coro conventual de São Francisco "durante mais de quarenta anos" (Mota, 2007: 36). Este era sobrinho de Fr. Sebastião das Onze-Mil-Virgens, definidor franciscano e também ele organista e compositor celebrado relacionado com o convento angrense. Dos restantes dois conventos masculinos de Angra (o de Santo António de capuchos e Nossa Senhora da Graça de agostinhos) não se conhece a existência de qualquer instrumento.

No que concerne aos quatro conventos femininos da cidade encontra-se 0 caso de dois órgãos gémeos construídos por Joaquim António Peres Fontanes. Ambos os instrumentos datam de 1793, sendo um construído para o convento de São Gonçalo de clarissas e o outro para o de Nossa Senhora da Conceição de religiosas concecionistas. No caso do convento de São Gonçalo, o órgão encontra-se atualmente no coro-alto da igreja, onde se crê que tenha sido o local onde foi instalado inicialmente. Este convento teve uma atividade litúrgico-musical assinalável uma vez que era uma comunidade numerosa, com número superior a sessenta religiosas. Após a extinção das ordens religiosas, foram recolhidas ao convento de São Gonçalo todas as religiosas dos outros conventos da ilha Terceira, o que manteve o edifício em atividade até bem tarde no século $\mathrm{XIX}$, até à morte da última religiosa, motivo pelo qual o instrumento permaneceu no seu local de origem (Costa, 1867:61-62).

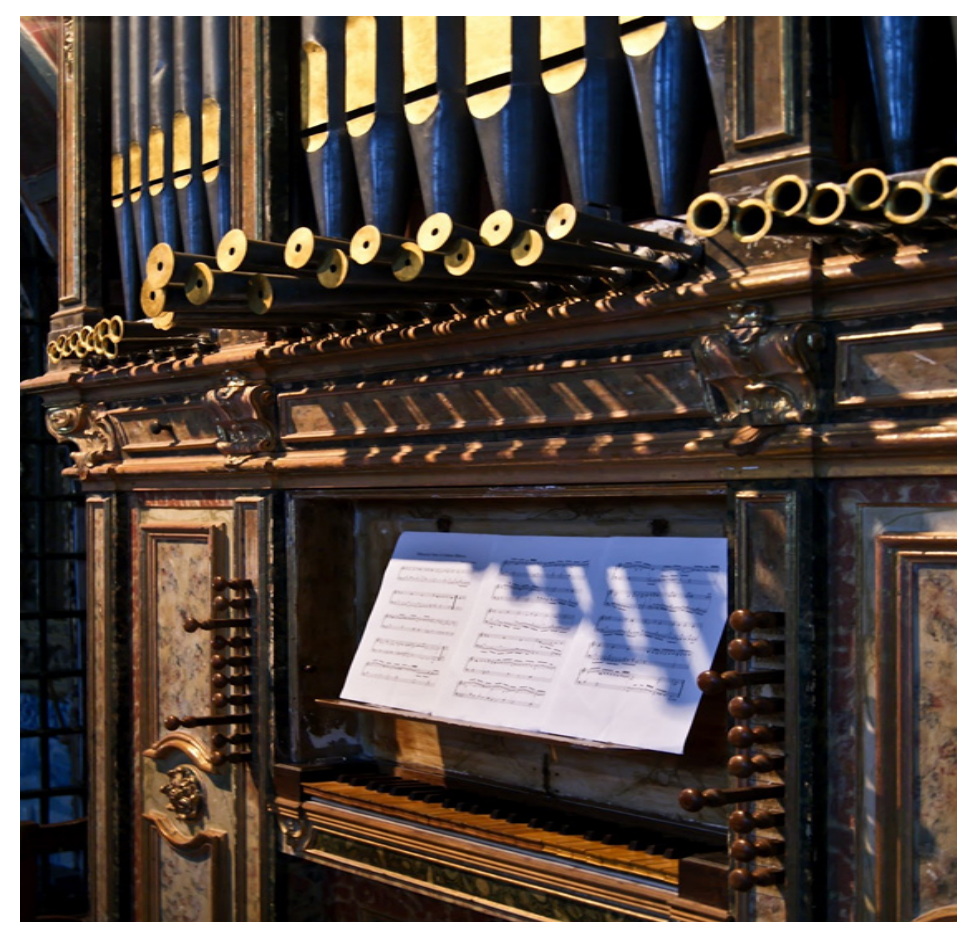

Figura 4. Pormenor do órgão da igreja do convento de São Gonçalo (foto César Araújo, 2012). 
No diz respeito ao outro órgão de Fontanes, do convento de Nossa Senhora da Conceição, após a extinção das ordens o recheio deste espaço reverteu para a Fazenda Nacional, que lá instalou o Hospital de Santo Espírito, gerido pela Misericórdia de Angra. $O$ órgão foi vendido para a igreja paroquial de Santa Bárbara. A Junta de Paróquia deliberou em sessão de 5 de fevereiro de 1837 que o instrumento fosse adquirido através de títulos de dívida pública ficando como credora a Fazenda Nacional. $O$ instrumento foi montado na igreja pelo organista Francisco José da Silveira, havendo necessidade de alargar o coreto onde seria instalado, assim como o arco da nave central que foi levantado (Andrade, 189I: 385).

Dos restantes conventos femininos de Angra, o de São Sebastião de capuchas e o de Nossa Senhora da Esperança de clarissas não foram ainda encontradas quaisquer referências quanto à presença de órgãos nas suas igrejas. Tal como o convento agostinho de Nossa Senhora da Graça, também estes dois conventos femininos foram demolidos, encontrando-se apenas alguns vestígios da sua estrutura primitiva o que não é suficiente para sequer ter uma ideia de como seria a arquitetura destas casas religiosas.

Em jeito de conclusão, a ilha Terceira constitui-se como um dos centros do arquipélago onde atualmente existe maior número de órgãos, em particular a cidade de Angra do Heroísmo. A existência destes instrumentos incorpora uma série de contextos históricos que se estendem através da própria história dos instrumentos, assim como das instituições a que estavam ligados. Na última década, o crescente número de festivais de órgão realizados na cidade que, por norma, têm seguido um modelo de roteiro, sendo tocados praticamente todos os instrumentos, têm vindo a contribuir para uma necessidade cada vez maior da existência de uma plataforma virtual com informação sobre os mesmos. No espírito das Humanidades Digitais, ao longo deste artigo pretendeu-se justificar a pertinência da criação de uma plataforma virtual em que a rede de relações entre os instrumentos e as instituições religiosas onde se encontram, assim como aquelas a que pertenceram anteriormente, é cada vez maior. Para além de objetos contemplativos, nomeadamente através da decoração das respetivas caixas, são também objetos sonoros que, embora grande parte do tempo silenciados, poderão ganhar som através de conteúdos multimédia (exemplos sonoros), incluindo-se também os indivíduos que a eles estiveram ligados, enquanto organeiros, organistas ou assistentes. Desta forma, julga-se que este itinerário virtual poderá criar uma paisagem sonora histórica, como também contemporânea, sobre estas importantes peças do património musical terceirense, com a profundidade da investigação científica que assegurará também a fidedignidade de um produto cultural relevante.

\section{Referências}

ALEGRIA, José A. O ensino e prática da música nas Sés de Portugal (da Reconquista aos fins do século XVI). Lisboa: Instituto de Cultura e Língua Portuguesa, 1985.

ANDRADE, Jerónimo E. d'.Topographia, ou descripção physica, politica, civil, ecclesiastica e histórica da ilha terceira dos açôres. Parte Primeira. Annotada pelo Vigario José Alves da Silva.Angra do Heroísmo: Livraria Religiosa - Editora, I89I. CORDENIZ, José N. Os órgãos de tubos de António Xavier Machado e Cerveira nos Açores. Dissertação de mestrado, Universidade Nova de Lisboa, 2010. COSTA, Félix J.Angra do Heroísmo, Ilha Terceira (Açores) (Os seus títulos, edi- 
fícios e estabelecimentos públicos).Angra do Heroísmo:Typ. do Governo Civil, 1867.

COSTA, Susana G. Açores: Nove Ilhas, Uma História. Berkeley: Institute of Governmental Studies/University of California, 2008.

CUNHA, Manuel A. da. Notas Históricas: Oferecidas á Mocidade Estudiosa Calhetense. Calheta, S. Jorge:Typographia de «O Dever», 1924.

DRUMOND, Francisco F.Annaes da Ilha Terceira. Tomo III.Angra do Heroísmo: Typ. de M. J. P. Leal, 1859.

DRUMOND, Francisco F. Apontamentos Topográficos, Políticos, Civis e Ecclesiásticos para a História das nove Illhas dos Açores servindo de suplemento aos Anais da Ilha Terceira. Angra do Heroísmo: Instituto Histórico da Ilha Terceira, 1990.

GABLENZ,T. Organs of Two Islands. Boletim do Instituto Histórico da llha Terceira. 27-28, p. 490-519, 1959-60.

JIMÉNEZ, Juan R. Cathedral Soundscapes: Some New Perspectives. In: Companion to Music in the Age of the Catholic Monarchs. ed.Tess Knighton, Leiden: Brill, 2017.

LOPES, Frederico. Da Praça às Covas - Memórias de uma Velha Rua. Boletim do Instituto Histórico da Ilha Terceira. 23-24, p. 5-376, I965-66.

MACHADO, Dinarte e DODERER, Gerhard. Inventário dos Órgãos dos Açores. Angra do Heroísmo: Presidência do Governo Regional dos Açores/Direção Regional da Cultura, 2012.

MARTINS, Francisco E. de O. Mobiliário Açoriano: elementos para o seu estudo. Angra do Heroísmo: Secretaria Regional da Educação e Cultura - Direcção Regional dos Assuntos Culturais, 1981.

MOTA, Valdemar. Santa Sé do Salvador. Igreja Catedral dos Açores. Angra do Heroísmo: Sé de Angra, 2007.

MOTA,Valdemar. Mais uma achega para a história do Orgão Grande da Sé Catedral de Angra. Ilha Terceira. 83, p. 7-8, 1986.

PEREIRA, Luís E. Mais Algumas notas sobre o "Orgão Grande” da Sé de Angra. Ilha Terceira. 87, p. 5-7, 1987.

PEREIRA, Luís E. Os Órgãos da Sé. Ilha Terceira. 82, p. 8-9, 1986.

SAMPAIO, Alfredo. Memória sobre A Ilha Terceira. Angra do Heroísmo: Imprensa Municipal, 1904.

WITTE, Charles-Martial. Documents Anciens des Archives du Chapitre d'Angra. Lusitania Sacra. 9, p. 129-253, 1972. 